Research Article

\title{
Impact of Sea Surface Temperature and Surface Air Temperature on Maximizing Typhoon Rainfall: Focusing on Typhoon Maemi in Korea
}

\author{
Jeonghyeon Choi $\mathbb{D},{ }^{1}$ Jeonghoon Lee, ${ }^{2}$ and Sangdan Kim $\mathbb{D}^{3}$ \\ ${ }^{1}$ Division of Earth Environmental System Science (Major in Environmental Engineering), Pukyong National University, \\ Busan 48513, Republic of Korea \\ ${ }^{2}$ Department of Civil and Environmental Engineering, Cleveland State University, Cleveland, OH 44115, USA \\ ${ }^{3}$ Department of Environmental Engineering, Pukyong National University, Busan 48513, Republic of Korea
}

Correspondence should be addressed to Sangdan Kim; skim@pknu.ac.kr

Received 28 February 2019; Revised 29 April 2019; Accepted 15 May 2019; Published 29 May 2019

Guest Editor: Sushil K. Dash

Copyright (c) 2019 Jeonghyeon Choi et al. This is an open access article distributed under the Creative Commons Attribution License, which permits unrestricted use, distribution, and reproduction in any medium, provided the original work is properly cited.

\begin{abstract}
In this study, the effects of surface air temperature (SAT) and sea surface temperature (SST) changes on typhoon rainfall maximization are analysed. Based on the numerically reproduced Typhoon Maemi, this study tried to maximize the typhooninduced rainfall by increasing the amount of saturated water vapour in the atmosphere and the amount of water vapour entering the typhoon. Using the Weather Research and Forecasting (WRF) model, which is one of the regional climate models (RCMs), the rainfall simulated by WRF while increasing the SAT and SST to various sizes at initial conditions and boundary conditions of the model was analysed. As a result of the simulated typhoon rainfall, the spatial distribution of total rainfall depth on the land due to the increase combination of SAT and SST showed a wide variety without showing a certain pattern. This is attributed to the geographical location of the Korean peninsula, which is a peninsula between the continent and the ocean. In other words, under certain conditions, typhoons may drop most of the rainfall on the southern sea of the peninsula before landing on the peninsula. For instance, the 6-hour duration maximum precipitation (MP) in Busan Metropolitan City was $472.1 \mathrm{~mm}$ when the SST increased by $2.0^{\circ} \mathrm{C}$. However, when the SST increased by $4.0^{\circ} \mathrm{C}$, the MP was found to be $395.3 \mathrm{~mm}$, despite the further increase in SST. This indicates that the MP at a particular area and the increase in temperature do not have a linear relationship. Therefore, in order to maximize typhoon rainfall, it is necessary to repeat the numerical experiment on various conditions and search for the combination of SAT and SST increase which is most suitable for the target typhoon.
\end{abstract}

\section{Introduction}

The probable maximum precipitation (PMP) is defined as the maximum amount of precipitation that can occur physically for a specific duration in a particular area $[1,2]$. The most widely applied method for estimating PMP is the hydrometeorological method, which statistically considers physical relationships with observational meteorological variables such as rainfall, dew point, and wind speed based on long-term observed weather data [3]. However, this PMP calculation method has a problem that it relies heavily on observation data [4]. It has been also reported that the physical relationship between the meteorological variables applied to the PMP estimation might not adequately reflect the processes of very complex atmosphere and precipitation [5].

In order to overcome the limitations of the PMP estimation method, researches for estimating the PMP using the regional climate model (RCM) have been conducted recently. In particular, Ohara et al. [6] and Ishida et al. [7-9] have proposed a method of maximizing rainfall occurred in the past by linking the spatial shifting of climate variables, maximizing relative humidity (RH), and increasing surface air temperature (SAT) using the fifth-generation Penn State/ NCAR mesoscale model (MM5). In Korea, studies have been 
carried out to estimate PMP by controlling climate variables using the Weather Research and Forecasting (WRF) model for Typhoon Rusa [10]. All of these studies commonly apply the method of maximizing the rainfall by changing the meteorological parameters of the initial and boundary conditions of the model after numerically reproducing the past rainfall events. Because RCM is used, the complex process of the atmosphere can be taken into consideration, and the dependence on observation data is relatively low compared to the existing PMP estimation method [9].

Due to global warming, SAT is increasing, and sea surface temperature (SST) is also increasing [11]. In particular, it is observed that the intensity of typhoon is getting stronger due to the rise of SST near the Western Pacific. In addition, since the warm pool around the Indian Ocean and the Pacific is expanded and the SST of the typhoon route approaching East Asia and Southeast Asia is increasing, the intensity of the typhoon is increasing, and the maximum reaching position of the typhoon is also rising [12]. It is also reported that the increase in SST around the Korean peninsula (especially during the summer season) affects the intensity of typhoons landing in China, Taiwan, Japan, Korea, and the Philippines [13]. If the increase in SAT and SST continues due to climate change, the intensity of typhoons generated in the Western Pacific will also increase gradually [14-17].

In fact, typhoons Rusa, Maemi, and Chaba, which had a great impact on the Korean peninsula in the past, suffered great damage because of the abnormally high SST, which caused the typhoon to land on the Korean peninsula while maintaining strong forces. Since the increase in the heat capacity of the surrounding ocean due to global warming and the rise of SST are likely to increase the energy supply of the typhoon, the potential risk of landing a super typhoon on the Korean peninsula is increasing gradually [18].

This study tried to maximize the rainfall by using WRF for the physical PMP estimation. The study was conducted based on the Maemi, a typhoon reproduced by Choi et al. [19] through the improvement of initial conditions and boundary conditions. Among the initial conditions and boundary conditions of WRF, this study tried to maximize typhoon rainfall by adjusting SAT, SST, and RH. The sensitivity of typhoon rainfall to SAT and SST increase by simulating typhoons in various SAT and SST conditions was also analysed.

\section{Materials and Methods}

2.1. Target Typhoon and Model Construction. Typhoon Maemi was a typhoon in September 2003 and landed on the Korean Peninsula, maintaining its maximum strength during the typhoon's life cycle, unlike most typhoons that affected the Korean peninsula. Recorded heavy rain and strong winds were generated because the Typhoon Maemi landed on the Korean peninsula with a steady supply of energy from the ocean due to abnormally high SST. Especially, although the Korean peninsula had been affected for a relatively short period of time, total rainfall depth of $100 \sim 450 \mathrm{~mm}$ was recorded in the southeastern part of the Korean peninsula. As a result, most of the Republic of Korea has been declared as a special disaster area, resulting in 131 deaths and missing persons and an enormous property damage of approximately KRW 4.2 trillion [20].

Choi et al. [19] numerically reproduced the Typhoon Maemi's rainfall by improving the initial conditions and boundary conditions through the observation data assimilation and the typhoon initialization technique using WRF. This study tried to maximize rainfall on land by typhoon based on reproduced Typhoon Maemi. WRF was composed of three domains considering the landing direction of the typhoon and the location of major rainfall. The horizontal resolution of each domain was set to $27 \mathrm{~km}, 9 \mathrm{~km}$, and $3 \mathrm{~km}$, respectively. In addition, a combination of physical options optimized by Choi et al. [19] was applied to this study. The details of the model are shown in Table 1. Figure 1 shows the spatial distribution of total rainfall depth reproduced by Choi et al. [19] and the spatially averaged rainfall time series in the southeastern part of the Korean peninsula.

2.2. Typhoon Rainfall Maximization. Typhoons, which generally land on the Korean peninsula, are supplied with energy sources in the Western Pacific and expand northward. At this time, the high SST plays an important role in raising the typhoon rainfall by increasing the amount of water vapour supplied to the typhoon. In addition, the high SAT affects the increase in saturated water vapour in the atmosphere. In other words, if the amount of saturated water vapour in the atmosphere is increased by the high SAT, and a large amount of water vapour is introduced into the typhoon due to the high SST, a great deal of rainfall is likely to occur.

Therefore, this study tried to maximize typhoon rainfall by increasing SAT, SST, and RH among climate variables closely related to rainfall. SAT will increase the amount of saturated water vapour in the atmosphere, SST will increase the amount of water vapour supplied to the typhoon, and additionally high $\mathrm{RH}$ will increase the amount of rainfall generated. Especially, considering the increase of SAT and SST due to global warming plays a major role in strengthening the typhoon's power, the increase of SAT and SST will have a great influence on the estimation of extreme rainfall in the future considering climate change.

To maximize the typhoon, the SAT and SST of the initial conditions and boundary conditions of the WRF were increased (see Figure 2(a)). However, since these two variables alone were not enough to generate the PMP, which is the physical upper limit of the rainfall, the RH of the boundary condition for entering the typhoon in Domain 3 was set to $100 \%$ (see Figure 2(b)). For reference, as a result of several numerical experiments, in the case that the $\mathrm{RH}$ of the boundary condition in all directions was set to $100 \%$, the water vapour of the typhoon was saturated early and most of the rainfall occurred in the East China Sea before the typhoon landed on the peninsula. This caused very little rainfall on land. In order to prevent this simulation result, the RH of the south boundary condition of Domain 3 was changed for a specific time, as shown in Table 2, in consideration of the typhoon route and location.

Figure 3 shows the procedure performed in this study to maximize the amount of rainfall caused by Typhoon Maemi. 
TABLE 1: Summary of the WRF model configuration [19].

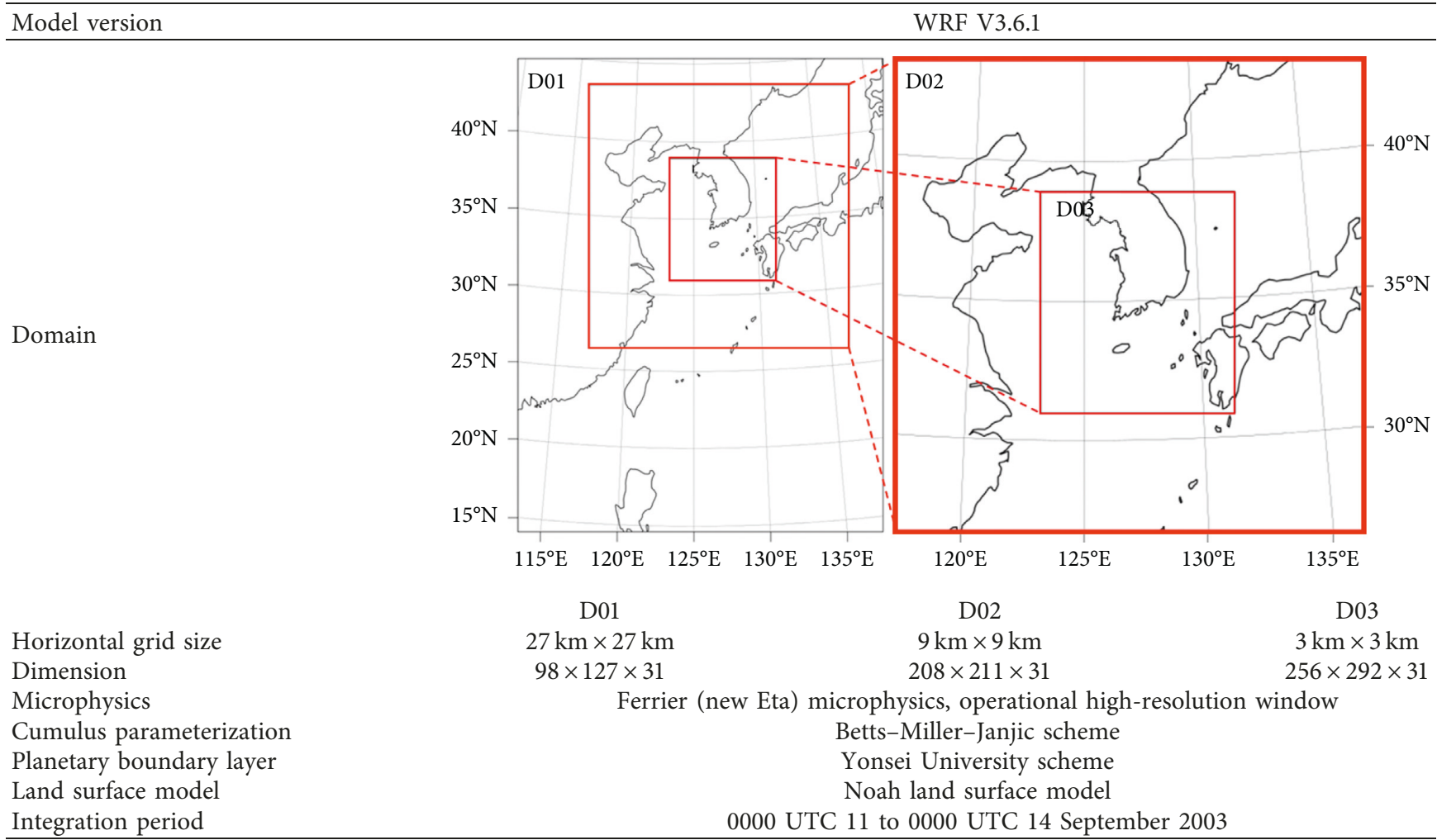
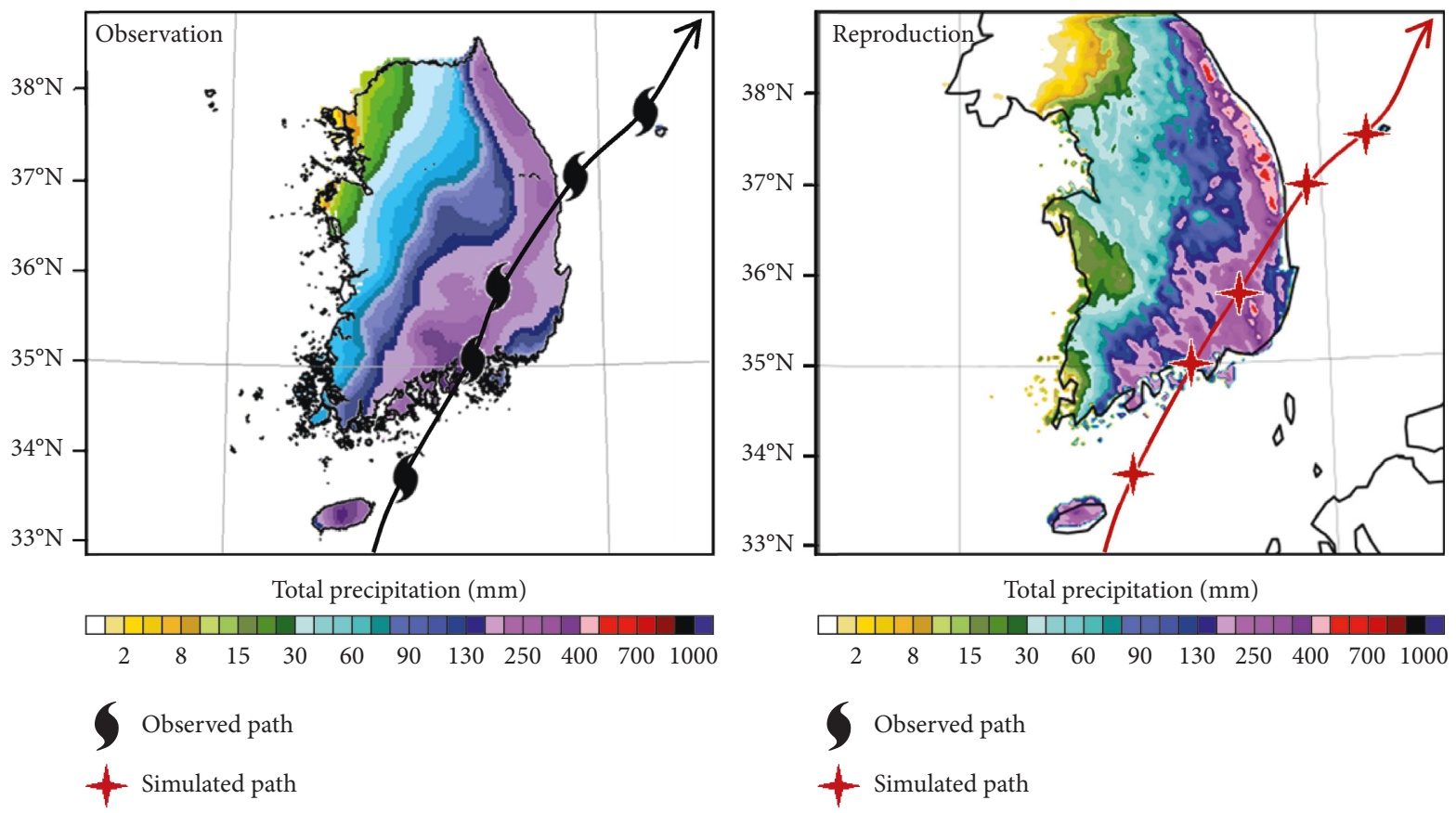

(a)

Figure 1: Continued. 


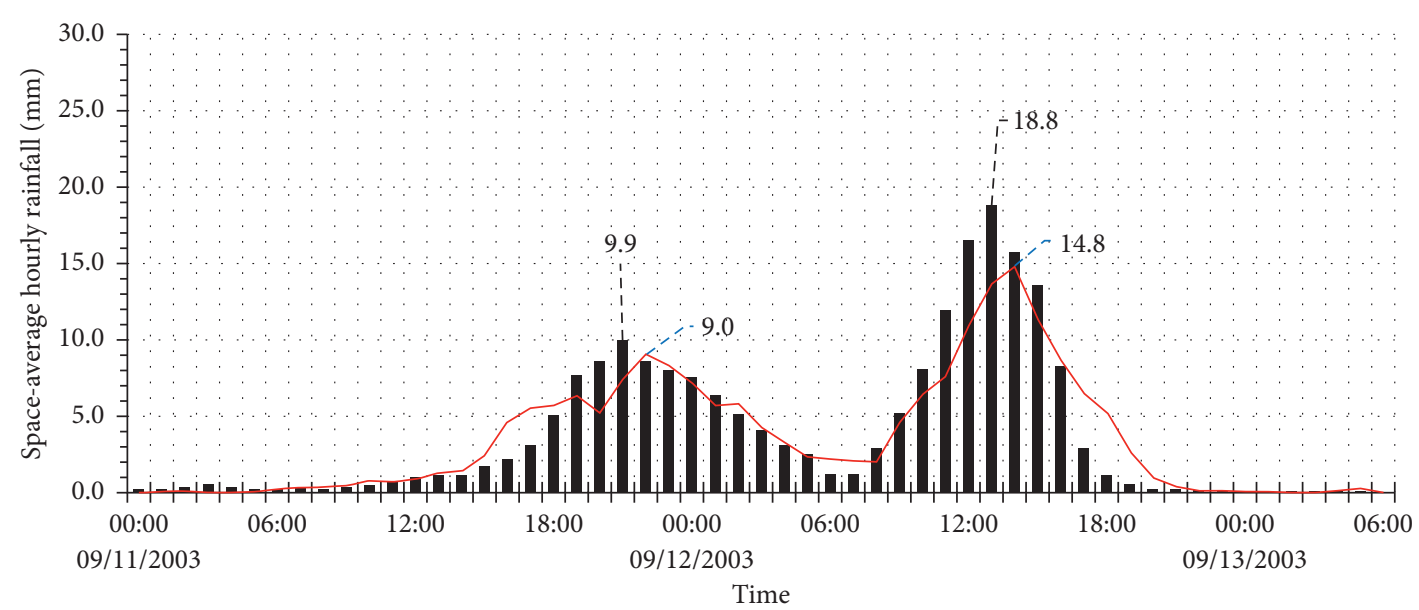

Observed

Simulated by Choi et al.[19]

(b)

FIGURE 1: Comparison of observed and simulated (a) total accumulated rainfall depth and (b) hourly rainfall time series in the southeastern part of the Korean peninsula, which is the major damaged area by Typhoon Maemi [19].

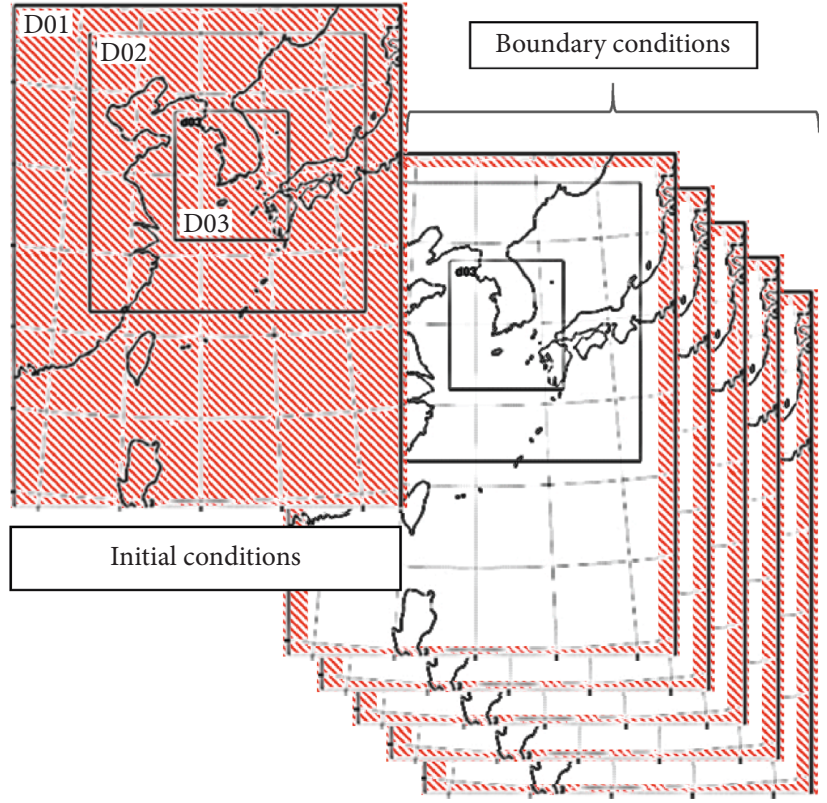

(a)

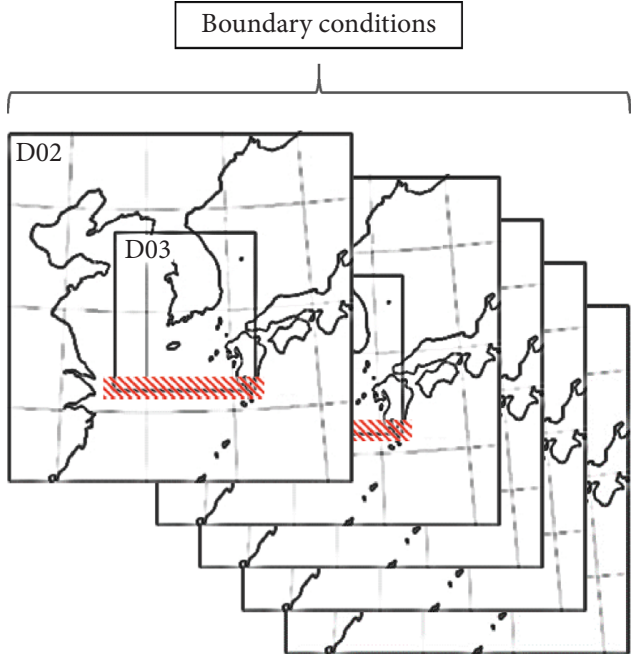

(b)

FIgURE 2: Change in initial and boundary conditions for (a) increase of SAT and SST and (b) maximization of RH.

TABLE 2: Modification of RH in the south boundary condition.

\begin{tabular}{lccccccc}
\hline Time & Before 06:00 (11-09-2003) & $06: 00$ & $12: 00$ & $18: 00$ & $00: 00(12-09-2003)$ & $\begin{array}{c}\text { After 06:00 } \\
(12-09-2003)\end{array}$ \\
\hline RH & Original condition & $100 \%$ & $100 \%$ & $100 \%$ & $100 \%$ & $100 \%$ & Original condition \\
\hline
\end{tabular}

First, after increasing SAT and SST of the initial condition and boundary condition of each domain, Domain 1 and Domain 2 were simulated. The RHs of the grids corresponding to the south boundary condition of Domain 3 in the simulated Domain 2 were modified to $100 \%$. The ndown method was then used to create a new boundary condition for Domain 3 from the modified Domain 2 results. The ndown method, built into the WRF model, is a function used for one-way nesting, which typically generates a lower domain boundary condition for the finer-grid resolution run using the results of the coarsegrid resolution run (upper domain). In this study, the boundary condition file of Domain 3 with RH of $100 \%$ in south 


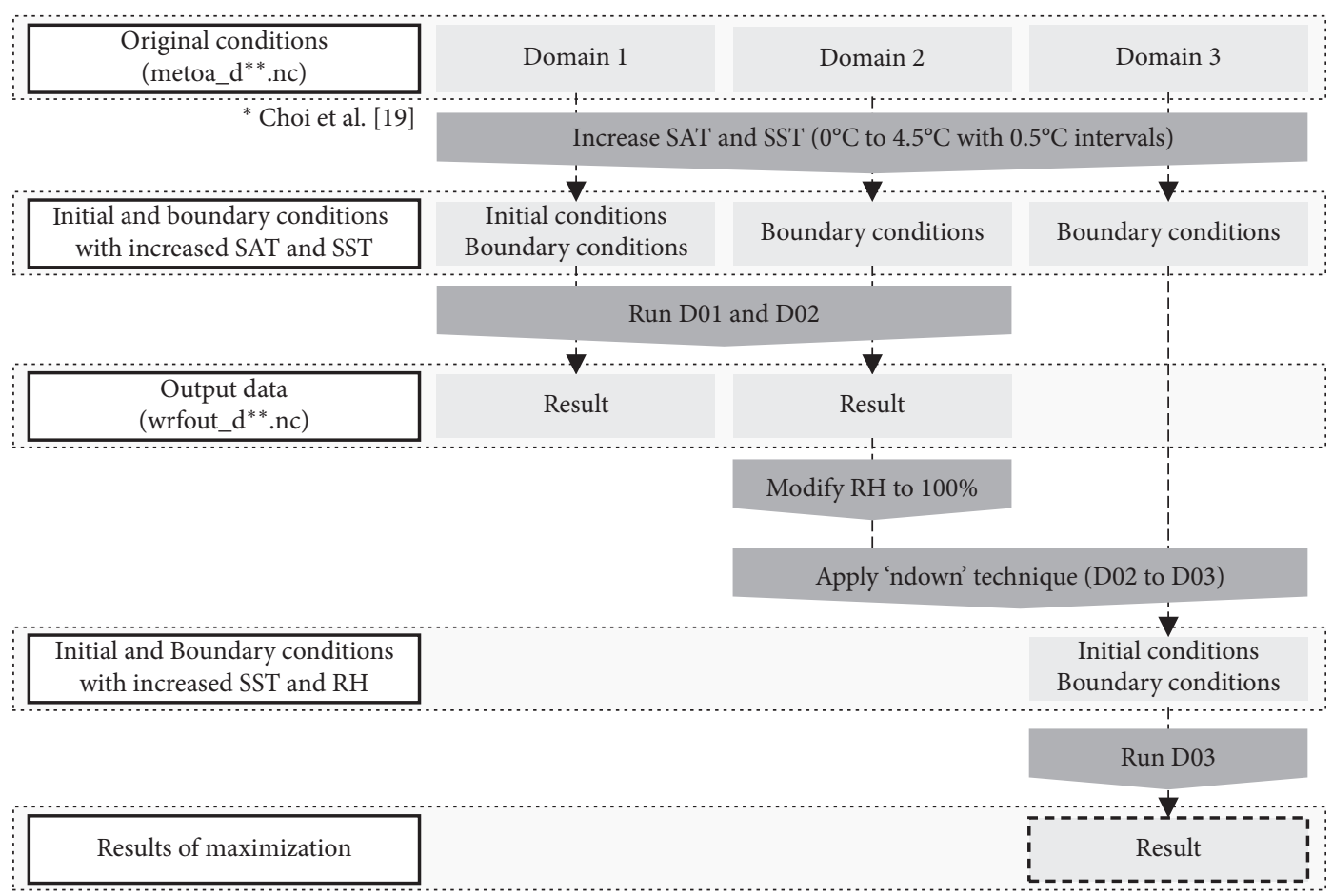

Figure 3: Procedure for maximizing Typhoon Maemi.

boundary was obtained by ndown method. For a more detailed description of the ndown method, see [21]. For reference, MATLAB was used to modify the SAT and SST of the initial and boundary conditions and the $\mathrm{RH}$ of the Domain 2 result.

\subsection{Sensitivity Analysis and Maximum Precipitation} Estimation. In order to examine the effect of increasing SAT and SST on the maximization of typhoon rainfall, numerical experiments were carried out by varying the SAT and SST increments (see Figure 4). Numerical experiments consisted of a total of 100 combinations, with SAT and SST increasing $0.5^{\circ} \mathrm{C}$ from $0^{\circ} \mathrm{C}$ to $4.5^{\circ} \mathrm{C}$, respectively, with $\mathrm{RH}$ set at $100 \%$, as shown in Table 2 . From the results of these numerical experiments, the effect of increasing SAT and SST on the total rainfall and spatial distribution of rainfall was analysed.

In fact, Singh and Oh [22] increased the Indian Ocean's monthly mean SST by $0.6^{\circ} \mathrm{C}$ in their study to investigate the impact of the interannual variability of Indian Ocean SST anomaly on Indian summer monsoon precipitation. However, this study focuses on maximizing the amount of rainfall caused by a specific typhoon event, not the amount of rainfall during the entire summer season, and the target area is also a relatively small local area consisting of sea and land around the Korean peninsula. Therefore, it is necessary to reflect the extreme change range that can occur temporarily, not the average increase in the SST increase range. For reference, Ishida et al. [9] changed the SAT from $0.0^{\circ} \mathrm{C}$ to $8.0^{\circ} \mathrm{C}$ to maximize precipitation for rainfall events over the American River watershed in Northern California. The SAT range in this study was set up with reference to Ishida et al. [9]. The range of increase in SST was also set from $0.0^{\circ} \mathrm{C}$ to $4.5^{\circ} \mathrm{C}$. In 2018, the SST on the East and the Yellow Sea of the
Korean Peninsula temporarily increased by $2.0^{\circ} \mathrm{C}$ to $4.0^{\circ} \mathrm{C}$ due to extreme heat wave events [23].

Finally, the proposed typhoon rainfall maximization procedure was applied to maximize the rainfall event by Typhoon Maemi, and then, the maximized rainfall depth was calculated for each duration of the Busan Metropolitan City in the southeast of the Korean Peninsula (see Figure 5). Maximized rainfall depth estimated in this study is defined as maximum precipitation (MP) for distinction from PMP estimated by hydrologic meteorological method. MP and PMP estimated by hydrometeorological method reported by Lee et al. [3] were compared.

\section{Results and Discussion}

3.1. Sensitivity of Total Rainfall Depth. Before estimating MP, the effects of increased SAT, SST, and $\mathrm{RH}$ on typhoon rainfall were explored. As shown in Figure 6, the sensitivity of the total rainfall depth occurred in the entire Domain 3 and the sensitivity of the total rainfall depth occurred in the land area of the Domain 3 were analysed.

In Figure 6, from the comparison of the results of reproduction with the results of the increase in $\mathrm{RH}$ alone $\left(\mathrm{SAT}+0.0^{\circ} \mathrm{C}\right.$ and $\left.\mathrm{SST}+0.0^{\circ} \mathrm{C}\right)$, it can be found that the amount of rainfall on the entire Domain 3 or land increases with increasing $\mathrm{RH}$. Therefore, it can be seen that $\mathrm{RH}$ plays an important role in maximizing the amount of rainfall caused by typhoons. However, the effects of SAT and SST on the maximization of rainfall caused by typhoons have been somewhat complicated.

The amount of rainfall in the entire Domain 3 shows an increasing pattern as SAT or SST increases (see Figure 6(a)). As the SAT increases for the same SST, the rainfall also 


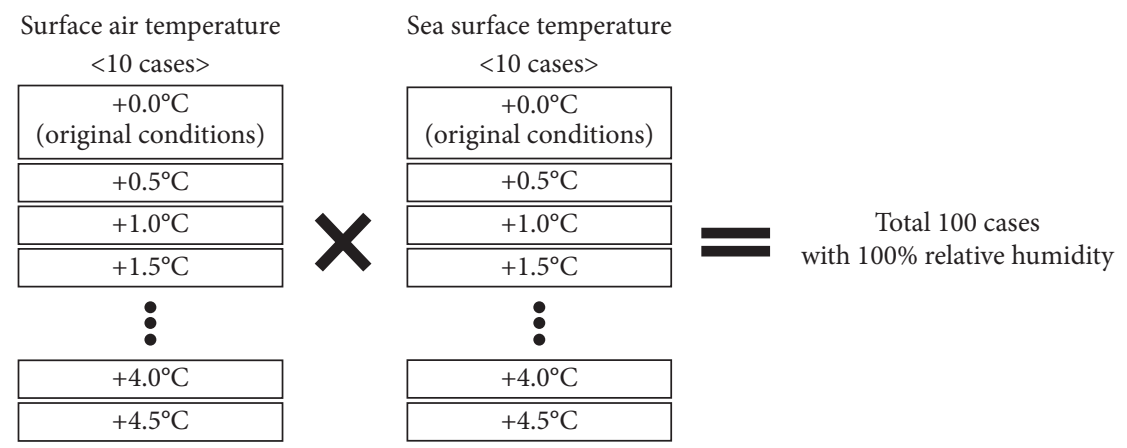

FIGURE 4: Composition of numerical experiments on SAT and SST incremental combinations.

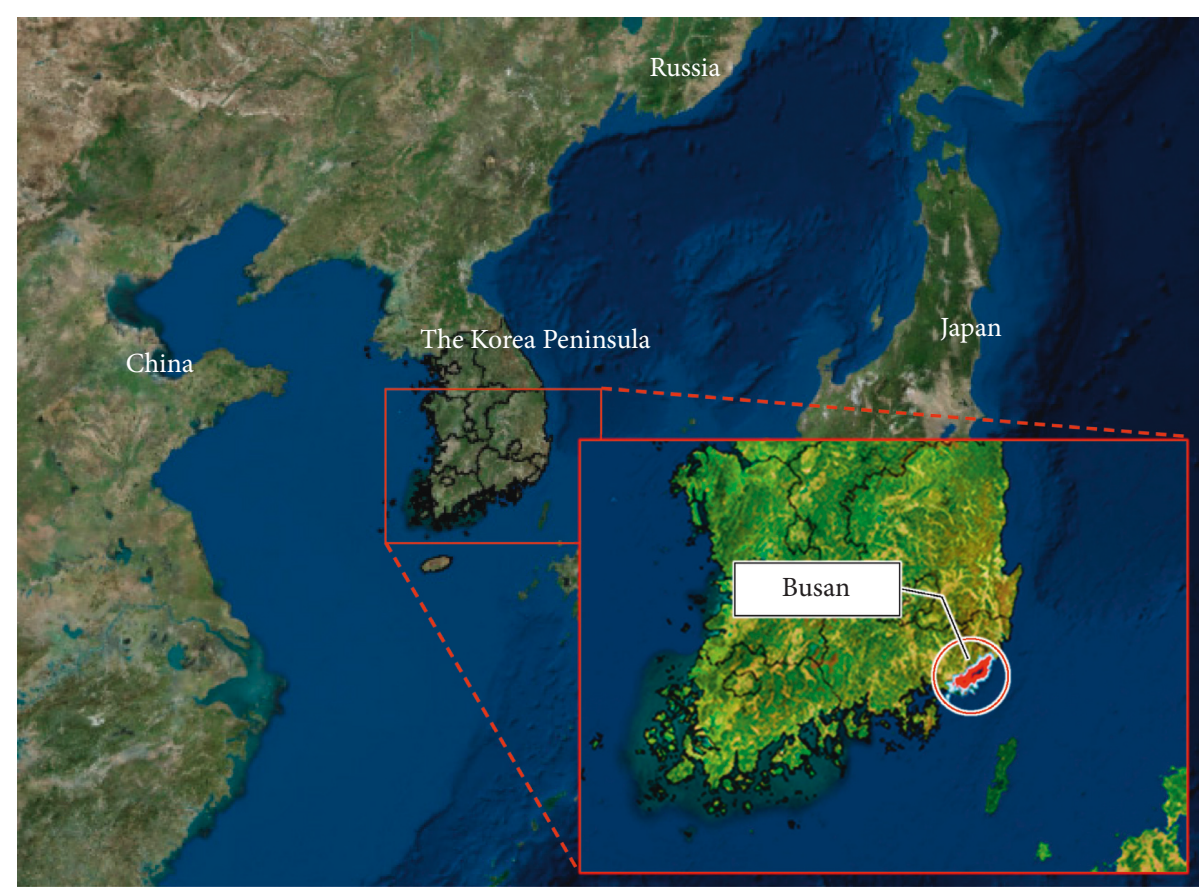

FIGURE 5: Location of Busan metropolitan.
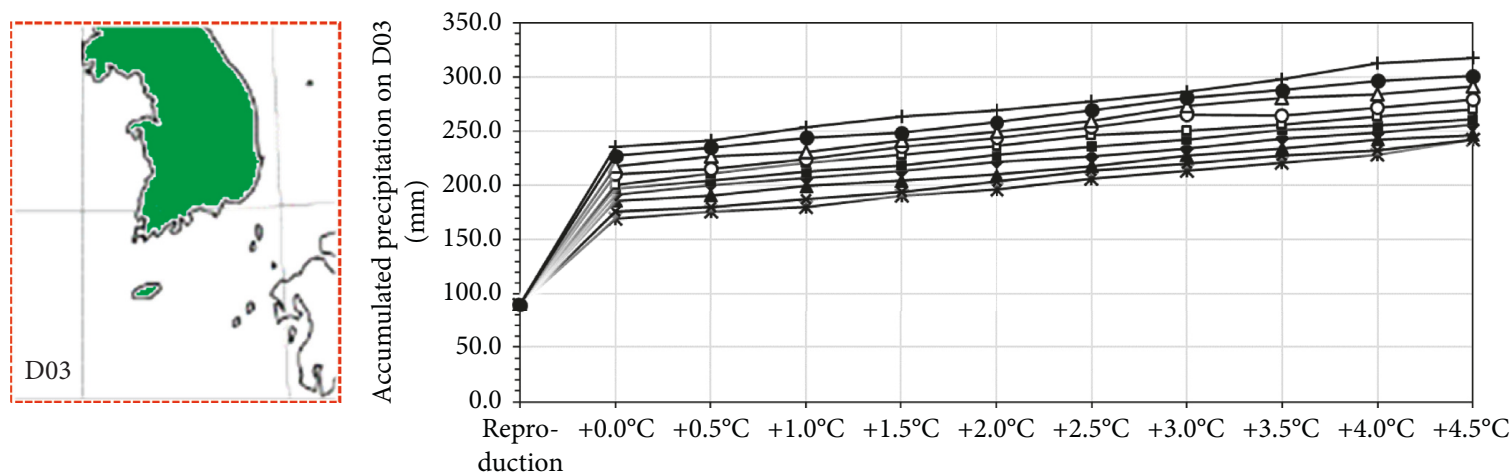

duction

Change amount of SST with RH 100\%

$\begin{array}{lll}\rightarrow \mathrm{SAT}+0.0^{\circ} \mathrm{C} & \rightarrow \mathrm{SAT}+2.0^{\circ} \mathrm{C} & \rightarrow \mathrm{SAT}+3.5^{\circ} \mathrm{C} \\ \rightarrow \mathrm{SAT}+0.5^{\circ} \mathrm{C} & \rightarrow \mathrm{SAT}+2.5^{\circ} \mathrm{C} & \rightarrow \mathrm{SAT}+4.0^{\circ} \mathrm{C} \\ \multimap \mathrm{SAT}+1.0^{\circ} \mathrm{C} & \rightarrow \mathrm{SAT}+3.0^{\circ} \mathrm{C} & \rightarrow \mathrm{SAT}+4.5^{\circ} \mathrm{C} \\ \rightarrow \mathrm{SAT}+1.5^{\circ} \mathrm{C} & & \end{array}$

(a)

Figure 6: Continued. 

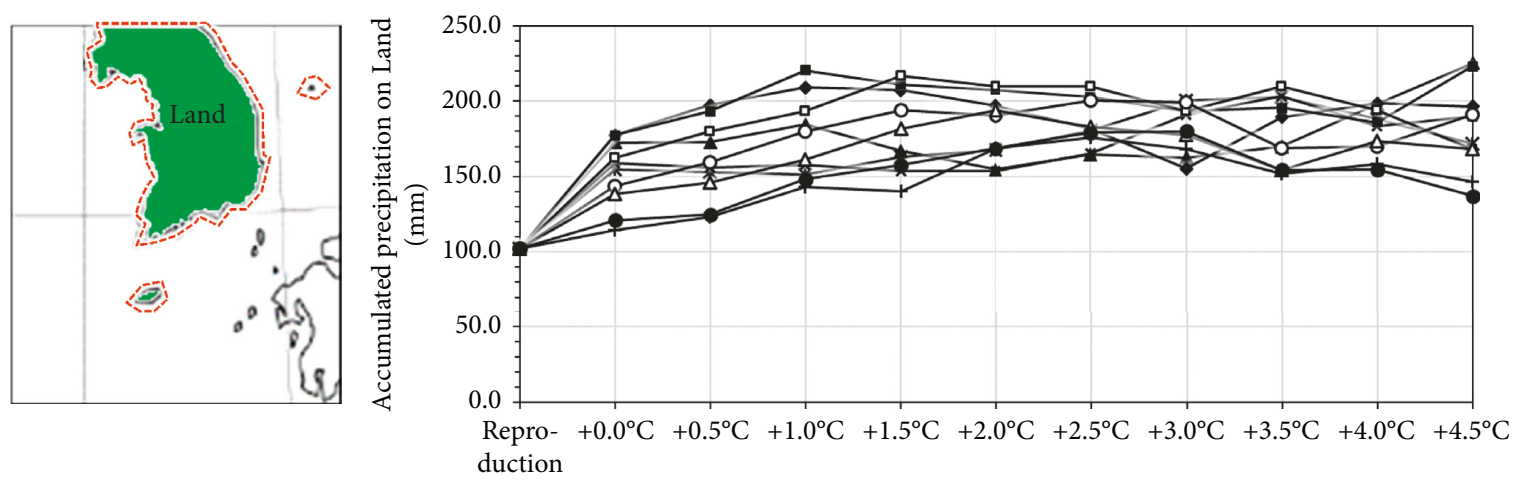

Change amount of SST with RH 100\%
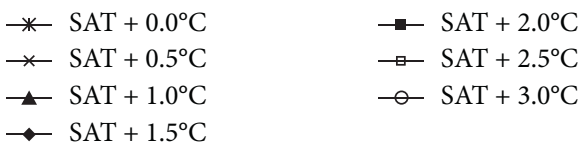

$\triangle \mathrm{SAT}+3.5^{\circ} \mathrm{C}$

$\rightarrow \mathrm{SAT}+4.0^{\circ} \mathrm{C}$

$\rightarrow \mathrm{SAT}+4.5^{\circ} \mathrm{C}$

(b)

FIgURE 6: Comparison of accumulated rainfall depth on (a) the entire D03 and (b) the land area of D03 for SAT and SST increases.

increases. As the SST increases for the same SAT, the rainfall also increases.

On the other hand, rainfall on land did not show a consistent relationship with SAT or SST increase. As shown in Figure 6(b), although the SAT or SST increases, the amount of rainfall decreases. For instance, in the case that the SST is increased from $0^{\circ} \mathrm{C}$ to $2.5^{\circ} \mathrm{C}$ while SAT is fixed at $4.0^{\circ} \mathrm{C}$ increase $\left(\mathrm{SAT}+4.0^{\circ} \mathrm{C}\right)$, the rainfall gradually increases. However, in the case that the SST is further increased, the rainfall decreases inversely. Also, it can be seen that the sensitivity of rainfall to the increase of SAT is very difficult to find a definite pattern.

3.2. Sensitivity of Spatial Distribution. As described in Section 3.1, the spatial distribution of total rainfall depth was examined in order to investigate the cause of the decrease in rainfall despite the increase of SAT or SST. Figure 7 shows some of the simulations of all combinations for SAT and SST increase. Similar to the observed data (see Figure 1(a)), it was observed that large rainfall occurred in the southeastern part of the Korean peninsula along the path of the typhoon.

Also, as the SAT and SST increase, the total rainfall depth increases. In the case of the same SAT increase, it was found that the total rainfall depth and range increase in the order of SST increment of $0.0^{\circ} \mathrm{C}$ (Figures $\left.7(\mathrm{a})-7(\mathrm{~d})\right), \quad 1.5^{\circ} \mathrm{C}$ (Figures $7(\mathrm{e})-7(\mathrm{~h})$ ), $3.0^{\circ} \mathrm{C}$ (Figures $7(\mathrm{i})-7(\mathrm{l})$ ), and $4.5^{\circ} \mathrm{C}$ (Figures $7(\mathrm{~m})-7(\mathrm{p}))$ for each SAT increase. The increase in rainfall due to the increase in SST can also be found by the same method.

However, the spatial distribution of total rainfall varied somewhat by SAT/SST increase combination. In particular, it can be seen that the location of the maximum rainfall and the amount of rainfall in the ocean were greatly changed depending on which SAT/SAT increase combination was applied. Comparing the combination of $100 \% \mathrm{RH} / \mathrm{SAT} 3^{\circ} \mathrm{C}$ increase/SST $3^{\circ} \mathrm{C}$ increase (see Figure $7(\mathrm{k})$ ) and the combination of $100 \% \mathrm{RH}$ only (see Figure $7(\mathrm{a})$ ), it can be seen that the amount of rainfall on the land had increased greatly in the southeast region of the peninsula as well as the increase in the amount of rainfall in the ocean. On the other hand, in the combination of $\mathrm{RH} 100 \% / \mathrm{SAT} \quad 4.5^{\circ} \mathrm{C}$ increase (see Figure $7(d)$ ), a lot of rainfall occurred in the southern sea of the peninsula, and the total rainfall was large, but the amount of rainfall on land was reduced. In other words, it was found that the spatial distribution of total rainfall depth varies greatly depending on which SAT increase/SST increase combination was applied, and the amount of rainfall on the land and its spatial pattern were influenced by how much rainfall occurred on the ocean before typhoon arrived on land. This is probably because the physics-based RCM reflects the interaction of the surface with the atmosphere relatively accurately.

3.3. Effect on Point Rainfall for Busan Metropolitan. In this study, to analyse the effect of SAT and SST on the rainfall of a specific area, the analysis was performed on Busan Metropolitan City, which was the main damage area caused by Typhoon Maemi, located in the southeast of the Korean peninsula. For comparison with PMP proposed by Lee et al. [3], MP was calculated using the spatially averaged rainfall of three grids of Domain 3 (i.e., the impact area is $27 \mathrm{~km}^{2}$ ). In addition, since the simulation results using the nesting grid system were generated from the input data composed of low resolution, it was not proper to calculate the MP by designating three specific grids included in Busan Metropolitan City. Therefore, in this study, maximum simulated rainfall in the range of $27 \mathrm{~km}^{2}$ for each combination of SAT/SST in Busan metropolitan area was regarded as MP. Figure 8 shows the estimated MP corresponding to the SAT/SST increment combination for various durations (1 hour and 6, 12, and 24 hours).

As can be seen in Figure 8, the MP of Busan Metropolitan City was not consistently proportional to the increase of SAT or SST. The influence of the SAT/SST increase combination applied on the result of MP was also changed depending on the duration. For instance, in the case of a short duration, the MP of SST $2.0^{\circ} \mathrm{C}$ increase combination (i.e., $472.1 \mathrm{~mm}$ for 


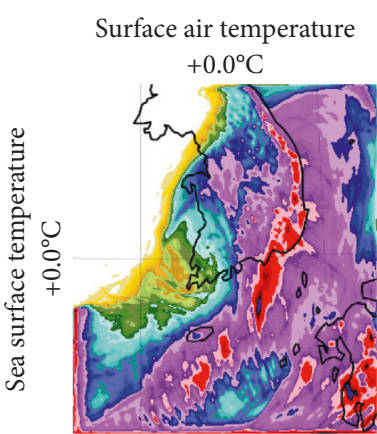

(a)

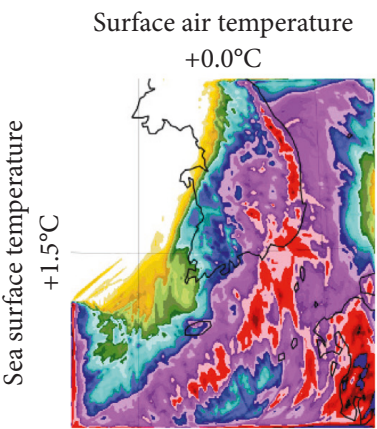

(e)

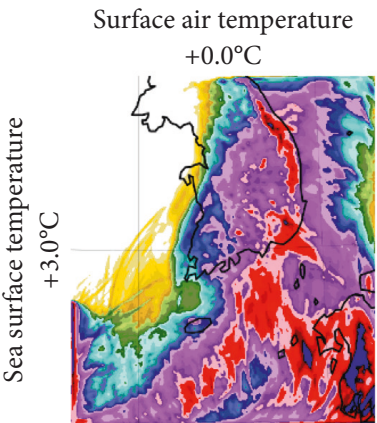

(i)

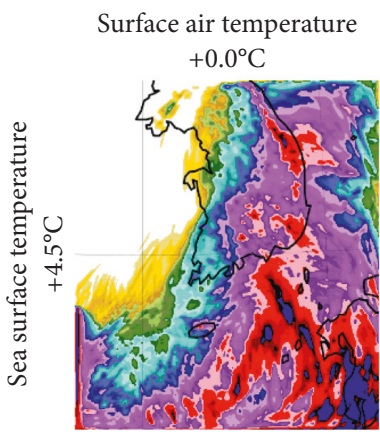

(m)

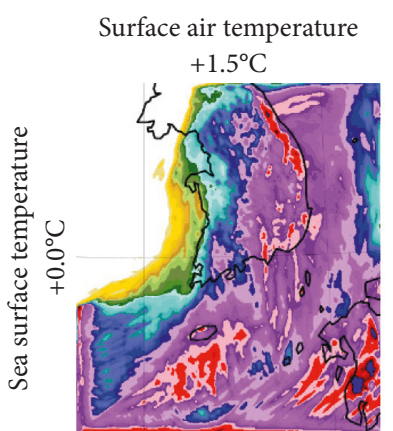

(b)

Surface air temperature $+1.5^{\circ} \mathrm{C}$

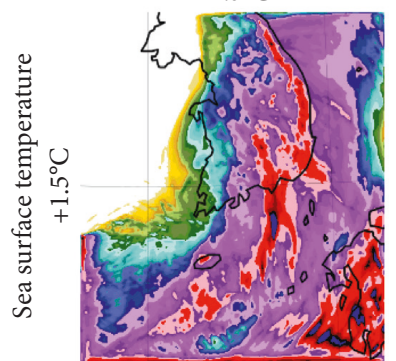

(f)

Surface air temperature $+1.5^{\circ} \mathrm{C}$

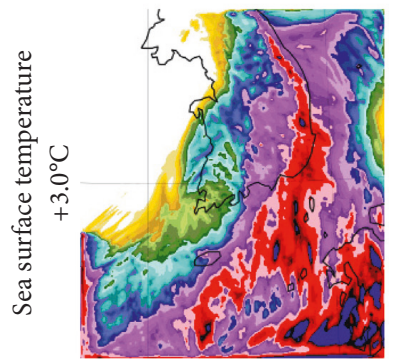

(j)

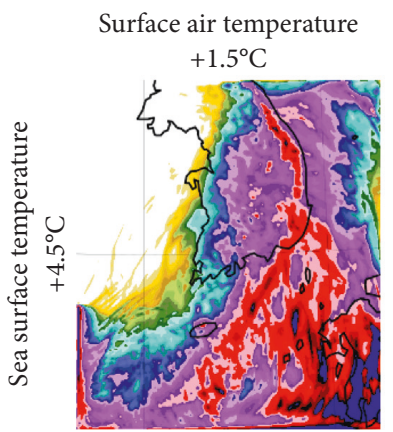

(n)

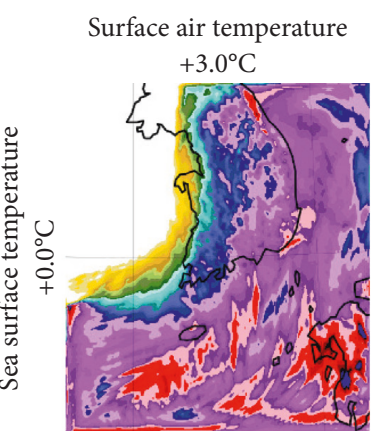

(c)

Surface air temperature $+3.0^{\circ} \mathrm{C}$

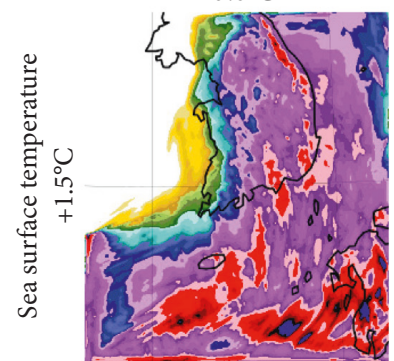

(g)

Surface air temperature $+3.0^{\circ} \mathrm{C}$

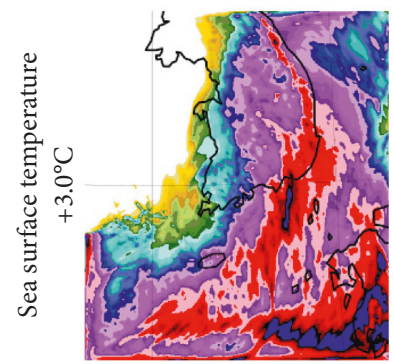

(k)

Surface air temperature $+3.0^{\circ} \mathrm{C}$

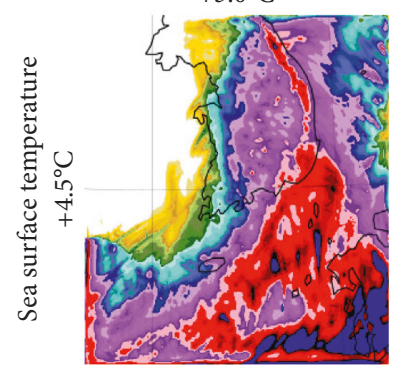

(o)

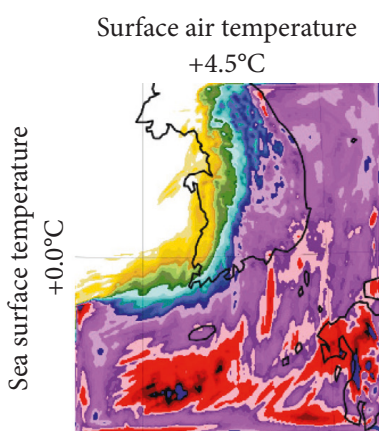

(d)

Surface air temperature $+4.5^{\circ} \mathrm{C}$

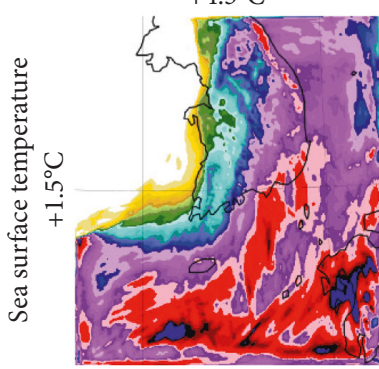

(h)

Surface air temperature

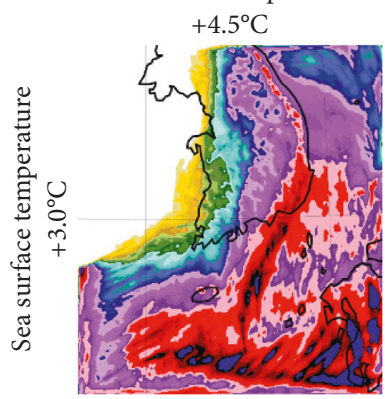

(1)

Surface air temperature

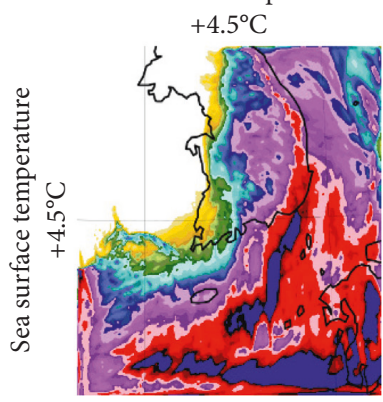

(p)

Total precipitation $(\mathrm{mm})$

\begin{tabular}{|l|l|l|l|l|l|l|l|l|l|l|l|l|l|l|l|l|l|l|l|l|}
\hline & & & & & & & & & & & & & & & & & & & & \\
\hline
\end{tabular}

FIGURE 7: Total rainfall depth and its spatial distribution for various SAT/SST combinations.

6 hours in SST 2.0) was estimated to be larger than the MP of SST $4.0^{\circ} \mathrm{C}$ increase combination (i.e., $359.3 \mathrm{~mm}$ for 6 hours in SST 4.0), whereas in the case of long durations, the MP of SST $4.0^{\circ} \mathrm{C}$ increase combination (i.e., $698.5 \mathrm{~mm}$ for 12 hours in SST 4.0) is estimated to be larger than the MP of SST $2.0^{\circ} \mathrm{C}$ increase combination (i.e., $646.1 \mathrm{~mm}$ for 12 hours in SST 2.0). The same results were shown for duration 1 hour (Figure 8(a)) and 24 hours (Figure $8(\mathrm{~d})$ ).

As mentioned above, these causes were reflected in the complex interaction of the surface and the atmosphere. 


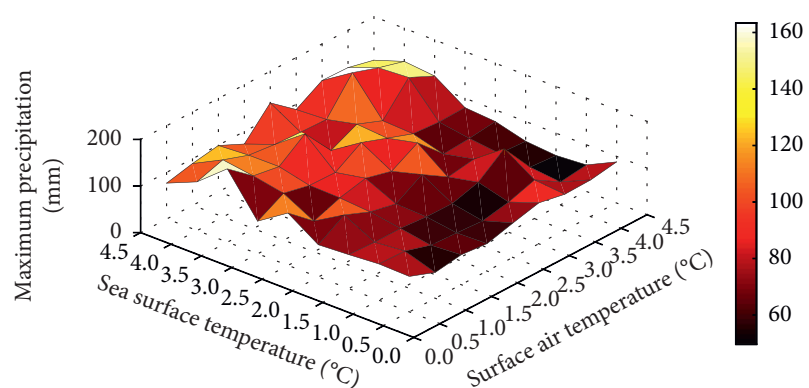

(a)

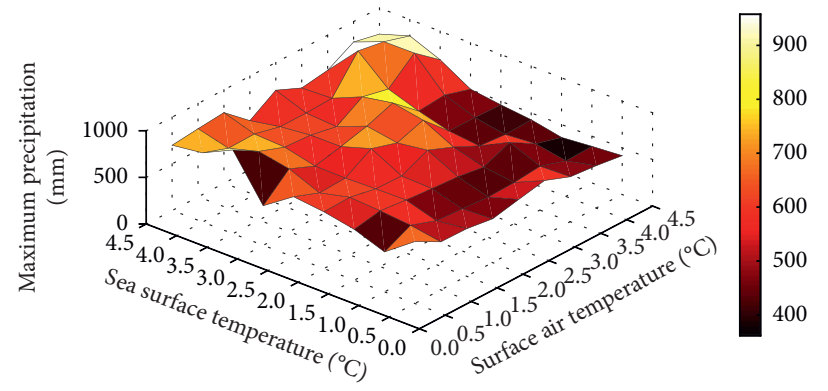

(c)

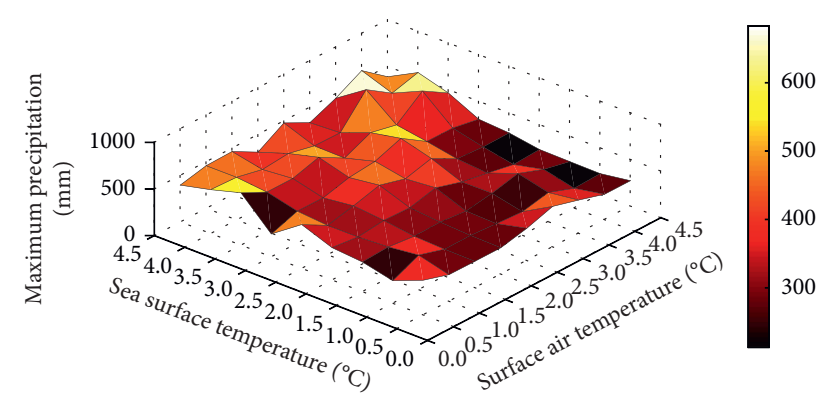

(b)

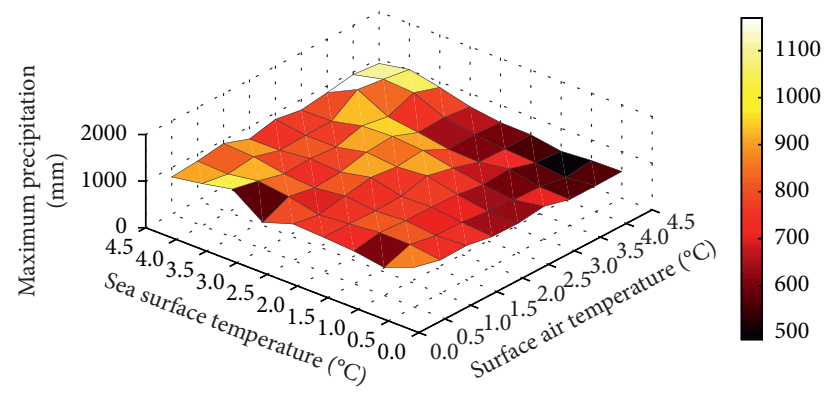

(d)

Figure 8: MP for duration (a) 1 hour, (b) 6 hours, (c) 12 hours, and (d) 24 hours at Busan.

Therefore, it is necessary to explore the optimal combination of SAT/SST by various numerical experiments in order to estimate the MP of a specific region through the increase of SAT and SST using physically based RCMs.

3.4. Estimation of Maximum Precipitation. From the results analysed so far, it has been shown that increasing the SAT or SST uniformly did not contribute to the production of MPs in a specific region using RCMs. In this study, two cases were selected among the MPs produced through numerical simulations: (1) SST/SAT increment combination in which the largest MP was simulated and (2) SAT/SST increment combination representing the MP that is closest to the previously reported hydrometeorological PMP. In addition, the selected MPs were compared with PMP calculated by hydrometeorological method of Lee et al. [3].

As shown in Figure 9, the combination of SAT $3.0^{\circ} \mathrm{C}$ increase/SST $3.5^{\circ} \mathrm{C}$ increase (MP 3.0-3.5) produced the largest MP. The MP 3.0-3.5 combination simulated $957.5 \mathrm{~mm} \mathrm{MP}$ at 12 hours of duration, which is approximately $32 \%$ greater than the PMP $(726.7 \mathrm{~mm})$ reported by Lee et al. [3]. However, even if the MP was estimated using the physically based RCM, the result of the MP that is more than $30 \%$ above the PMP, which means the maximum amount of precipitation that can occur physically, was considered to be somewhat unreasonable.

Therefore, in this study, a combination that produces the most similar results to the previously reported PMPs was explored. As a result, it was confirmed that the combination of SAT $2.5^{\circ} \mathrm{C}$ increase/SST $3.0^{\circ} \mathrm{C}$ increase (MP 2.5-3.0) produced MPs closest to the conventional PMPs. The MP 2.5-3.0 combination simulated a rainfall depth $(736.5 \mathrm{~mm})$ greater than PMP $(726.7 \mathrm{~mm})$ for duration of 12 hours, but

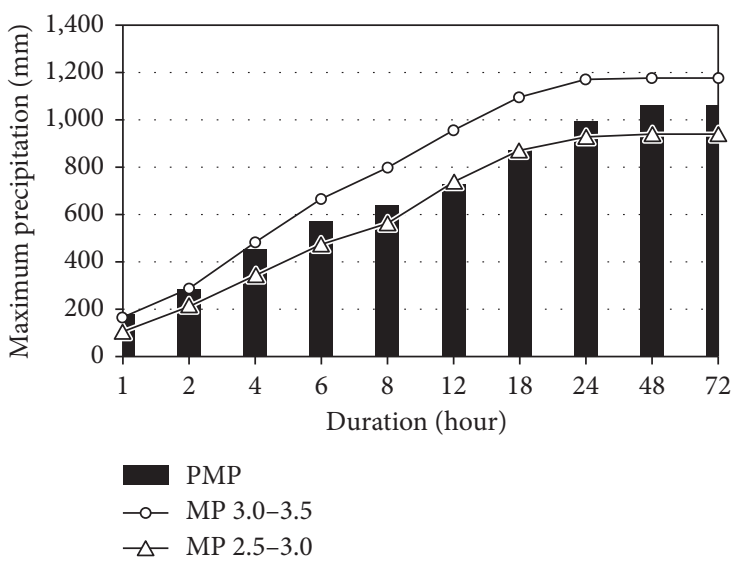

Figure 9: Comparison of PMP and selected MPs.

the difference between the two values was only about $1 \%$, so it was judged to be acceptable. In addition, the MP 2.5-3.0 combination simulated a MP of about $6 \%$ smaller than PMP $(930.9 \mathrm{~mm})$ for duration of 24 hours, but this was also considered reliable enough considering the uncertainty of PMP estimation.

When MP is calculated using the physically based RCM, the rainfall is simulated at the computational time interval that drives the model. Therefore, not only the maximum rainfall depth for various durations but also the temporal distribution of total rainfall depth can be obtained. That is, there is no need to configure separately a virtual rainfall temporal distribution. This means that the results of this study can be used directly as input data to rainfall-runoff models for flood inundation maps or emergency action plans under the occurrence of mega-disaster scenarios. Figure 10 shows the rainfall hyetograph (bar graph) and 


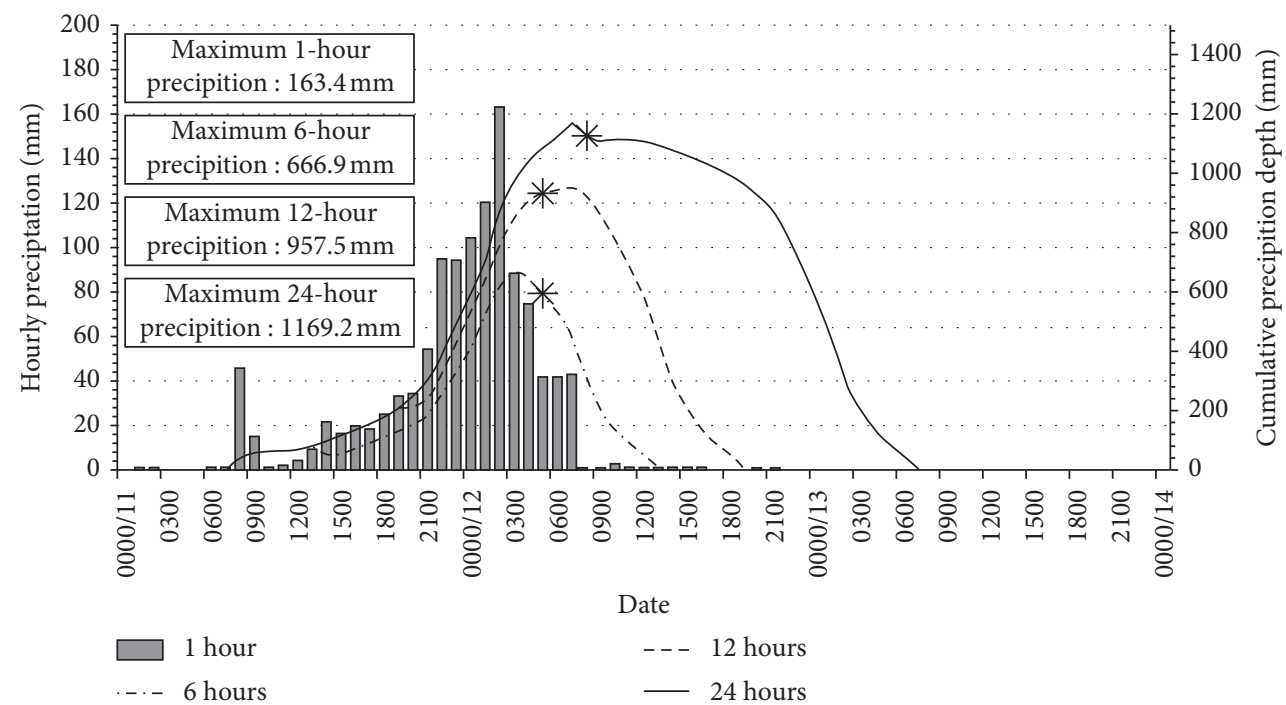

(a)

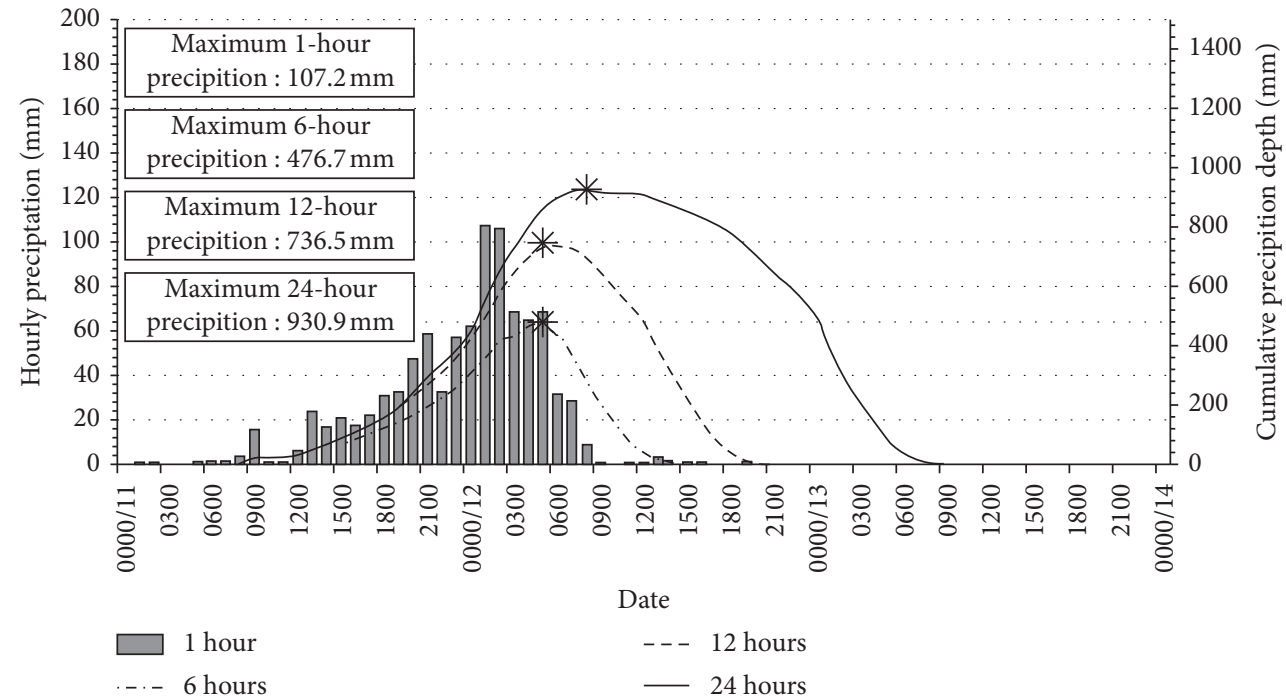

(b)

FIGURE 10: Rainfall hyetograph and rainfall depth for several durations produced at Busan using (a) MP 3.0-3.5 combination and (b) MP 2.5-3.0 combination.

rainfall depth for several durations (line graph) that can be obtained as a result of two selected combinations.

\section{Conclusion}

In this study, the influence of increasing SAT and SST on the typhoon path (see Figure 1(a)) on the total rainfall depth was analysed using WRF. In addition, the spatially averaged MP of $27 \mathrm{~km}^{2}$ was calculated for Busan Metropolitan City and compared with PMP estimated by hydrometeorological method.

As a result of analysing the effect of increase of SAT and SST on the total rainfall depth, total rainfall amount in land area of applied domain did not show an explicit relationship with increase of SAT and SST. Since physically based RCMs reflect the complex interactions of the surface and atmosphere, the spatial distribution of rainfall produced by typhoons in peninsular terrain varies greatly in response to changes in ambient climatic conditions. Therefore, despite the increase of SAT and SST, the amount of rainfall in the land decreases. That is, even if the SAT or SST is greatly increased, the amount of rainfall occurring in a specific area does not increase as intended. The results of estimating the MP of Busan Metropolitan City showed no relation regardless of which SAT or SST increment combination was applied. For instance, the duration 6-hour MPs in the Busan area calculated through a total of 100 SAT/SST combination showed a wide range of rainfall amount results ranging from $361.7 \mathrm{~mm}\left(\mathrm{SAT}+4.0^{\circ} \mathrm{C}\right.$ and $\left.\mathrm{SST}+1.0^{\circ} \mathrm{C}\right)$ to $957.5 \mathrm{~mm}\left(\mathrm{SAT}+3.0^{\circ} \mathrm{C}\right.$ and $\left.\mathrm{SST}+3.5^{\circ} \mathrm{C}\right)$. However, the MP of combination of $\mathrm{SAT}+4.0^{\circ} \mathrm{C}$ and SST $+4.0^{\circ} \mathrm{C}$ was estimated to be $720.3 \mathrm{~mm}$ smaller than 
$957.5 \mathrm{~mm}\left(\mathrm{SAT}+3.0^{\circ} \mathrm{C}\right.$ and SST $\left.+3.5^{\circ} \mathrm{C}\right)$. Therefore, it is difficult to produce extreme rainfall scenarios in a specific region simply by increasing the SAT or SST as in the method of moisture maximization for estimating PMPs, when producing MP using RCMs. This means that numerous numerical experiments on various SAT/SST increment combinations are needed.

When the rainfall of Typhoon Maemi was maximized by using WRF, the MP of Busan Metropolitan City was estimated to be the highest when SAT $3.0^{\circ} \mathrm{C}$ increase/SST $3.5^{\circ} \mathrm{C}$ increase combination was applied. Also, the SAT $2.5^{\circ} \mathrm{C}$ increase/SST $3.0^{\circ} \mathrm{C}$ increase combination produced the most similar MP as the PMP reported in the literature. The proposed method of maximizing the typhoon rainfall is expected to contribute to the improvement of the PMP estimation method. Since produced MPs provide detailed temporal distribution of the total rainfall depth as well as total rainfall depth for various durations and impact areas, they can be applied directly as input data of rainfall-runoff models for the design of massive hydraulic structures and the establishment of flood inundation maps and emergency action plans caused by mega disasters.

However, since the spatial distribution of rainfall is heavily influenced by the changes in the surrounding climatic conditions, if the meteorological variables other than SST/SAT/RH applied in this study are changed, there is a possibility that MP is also changed. Therefore, in order to produce extreme rainfall scenarios in specific regions using physically based RCMs, numerical experiments using a combination of varying climate variables rather than unconditional changes in specific climate variables will be needed. Therefore, future studies on various climate variables affecting rainfall caused by typhoons, such as air pressure, wind velocity, and SAT, SST, and RH, are required to maximize typhoon rainfall using RCMs.

\section{Data Availability}

The data used to support the findings of this study are available from the corresponding author upon request.

\section{Conflicts of Interest}

The authors declare that they have no conflicts of interest.

\section{Acknowledgments}

This work was supported by the Korea Environmental Industry and Technology Institute (KEITI) grant funded by the Ministry of Environment (RE201901073).

\section{References}

[1] E. M. Hansen, L. C. Schreiner, and J. F. Miller, Application of Probable Maximum Precipitation Estimates-United States East of the 105th Meridian, Hydro Meterological Report No. 52, National Weather Service, Washington, DC, USA, 1982.

[2] World Meteorological Organization (WMO), Manual for Estimation of Probable Maximum Precipitation, World
Meteorological Organization (WMO), Geneva, Switzerland, 1986.

[3] O. Lee, Y. Park, E. S. Kim, and S. Kim, "Projection of Korean probable maximum precipitation under future climate change scenarios," Advances in Meteorology, vol. 2016, Article ID 3818236, 16 pages, 2016.

[4] S. M. Papalexiou and D. Koutsoyiannis, "A probabilistic approach to the concept of probable maximum precipitation," Advances in Geosciences, vol. 7, pp. 51-54, 2006.

[5] D. J. Abbs, "A numerical modeling study to investigate the assumptions used in the calculation of probable maximum precipitation," Water Resources Research, vol. 35, no. 3, pp. 785-796, 1999.

[6] N. Ohara, M. L. Kavvas, S. Kure, Z. Q. Chen, S. Jang, and E. Tan, "Physically based estimation of maximum precipitation over American River watershed, California," Journal of Hydrologic Engineering, vol. 16, no. 4, pp. 351-361, 2011.

[7] K. Ishida, M. L. Kavvas, S. Jang, Z. Q. Chen, N. Ohara, and M. L. Anderson, "Physically based estimation of maximum precipitation over three watersheds in northern California: atmospheric boundary condition shifting," Journal of $\mathrm{Hy}$ drologic Engineering, vol. 20, no. 4, article 04014052, 2015.

[8] K. Ishida, M. L. Kavvas, S. Jang, Z. Q. Chen, N. Ohara, and M. L. Anderson, "Physically based estimation of maximum precipitation over three watersheds in northern California: relative humidity maximization method," Journal of Hydrologic Engineering, vol. 20, no. 10, article 04015014, 2015.

[9] K. Ishida, N. Ohara, M. L. Kavvas, Z. Q. Chen, and M. L. Anderson, "Impact of air temperature on physicallybased maximum precipitation estimation through change in moisture holding capacity of air," Journal of Hydrology, vol. 556, pp. 1050-1063, 2018.

[10] J. Lee, J. Choi, O. Lee, and S. Kim, "Estimation of probable maximum precipitation in Korea using a regional climate model," Water, vol. 9, no. 4, pp. 1-12, 2017.

[11] IPCC, "Contribution of working groups I, II and III to the fifth assessment report of the intergovernmental panel on climate change," in Climate Change 2014: Synthesis Report, R. K. Pachauri and L. A. Meyer, Eds., IPCC, Geneva, Switzerland, 2014.

[12] E. Weller, S. Min, W. Cai, F. W. Zwiers, Y. Kim, and D. Lee, "Human-caused indo-pacific warm pool expansion," Science Advances, vol. 2, no. 7, article e1501719, 2016.

[13] W. Mei and S.-P. Xie, "Intensification of landfalling typhoons over the northwest pacific since the late 1970s," Nature Geoscience, vol. 9, no. 10, pp. 753-757, 2016.

[14] F. Laliberte, J. Zika, L. Mudryk, P. J. Kushner, J. Kjellsson, and K. Doos, "Constrained work output of the moist atmospheric heat engine in a warming climate," Science, vol. 347, no. 6221, pp. 540-543, 2015.

[15] National Institute of Meteorological Research (NIMR), Understanding Climate Change II-Climate Change on the Korean Peninsula: Present and Future, National Institute of Meteorological Research, Seogwipo, Republic of Korea, 2009, in Korean.

[16] K. Tsuboki, M. K. Yoshioka, T. Shinoda, M. Kato, S. Kanada, and A. Kitoh, "Future increase of supertyphoon intensity associated with climate change," Geophysical Research Letters, vol. 42, no. 2, pp. 646-652, 2015.

[17] World Meteorological Organization (WMO), The Second Assessment Report on the Influence of Climate Change on Tropical Cyclones in the Typhoon Committee Region, ESCAP/ WMO Typhoon Committee, Geneva, Switzerland, 2012. 
[18] J. Kim, C. Son, and Y. Moon, "Super typhoon haiyan and future typhoon forecast," Water for Future, vol. 47, no. 2, pp. 49-54, 2014, in Korean.

[19] J. Choi, J. Lee, H.-G. Jeong, J. Jang, and S. Kim, "Effect of improvement of initial and boundary conditions in WRF model on simulating typhoon rainfall," Journal of the Korean Society of Hazard Mitigation, vol. 18, no. 2, pp. 445-454, 2018, in Korean.

[20] Gangwon Regional Meteorological Administration (GRMA), Gangwon-Do Typhoon White Paper, Gangwon Regional Meteorological Administration, Gangwon-Do, Republic of Korea, 2013, in Korean.

[21] National Center for Atmospheric Research (NCAR), ARW Version 3 Modeling System User's Guide, National Center for Atmospheric Research (NCAR), Boulder, CO, USA, 2015.

[22] G. P. Singh and J.-H. Oh, "Impact of Indian Ocean sea-surface temperature anomaly on Indian summer monsoon precipitation using a regional climate model," International Journal of Climatology, vol. 27, no. 11, pp. 1455-1465, 2007.

[23] Korean Meteorological Administration (KMA), 2018 Abnormal Climate Report, Korea Meteorological Administration, Seoul, Republic of Korea, 2019, in Korean. 

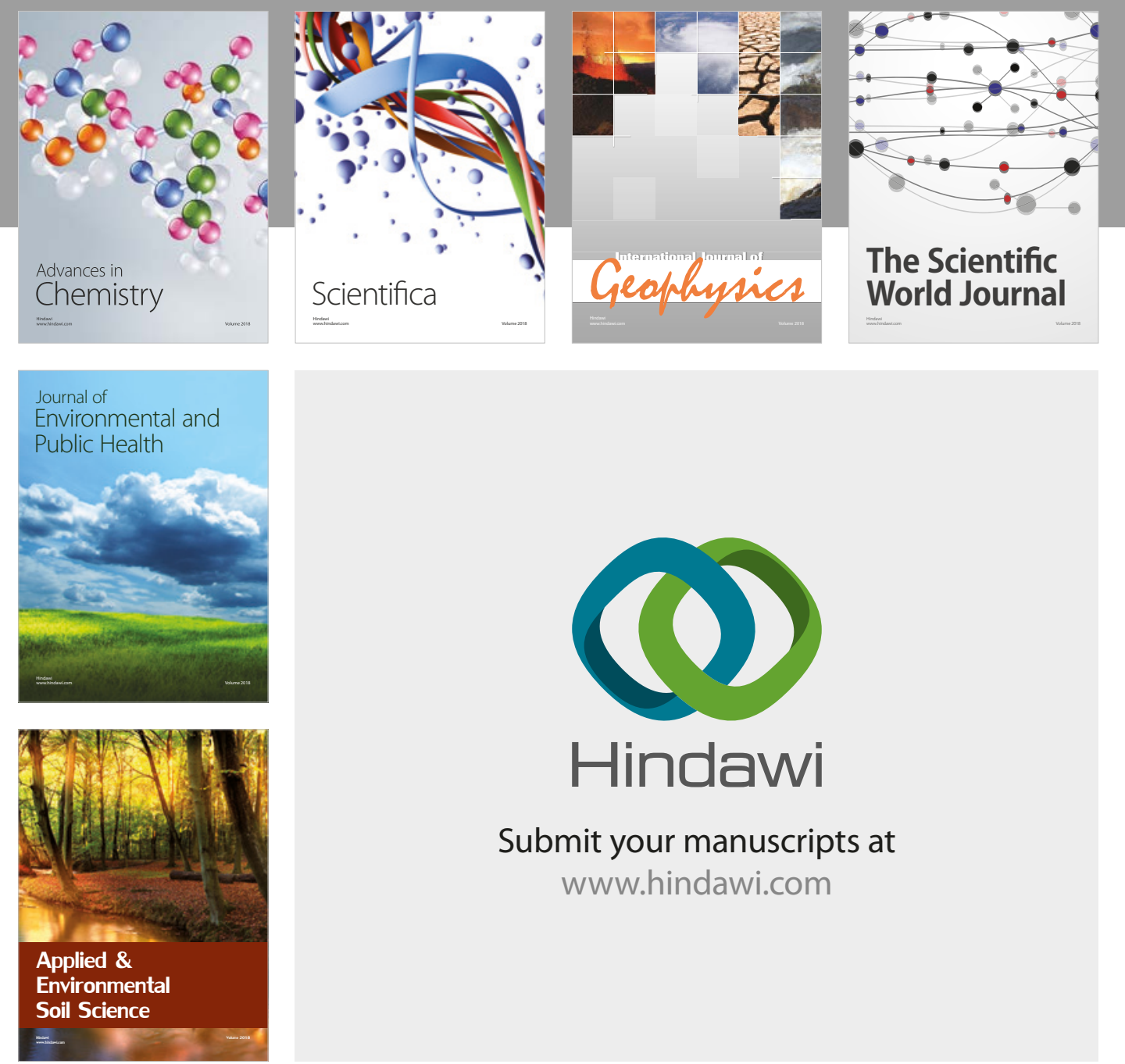

The Scientific

\section{World Journal}
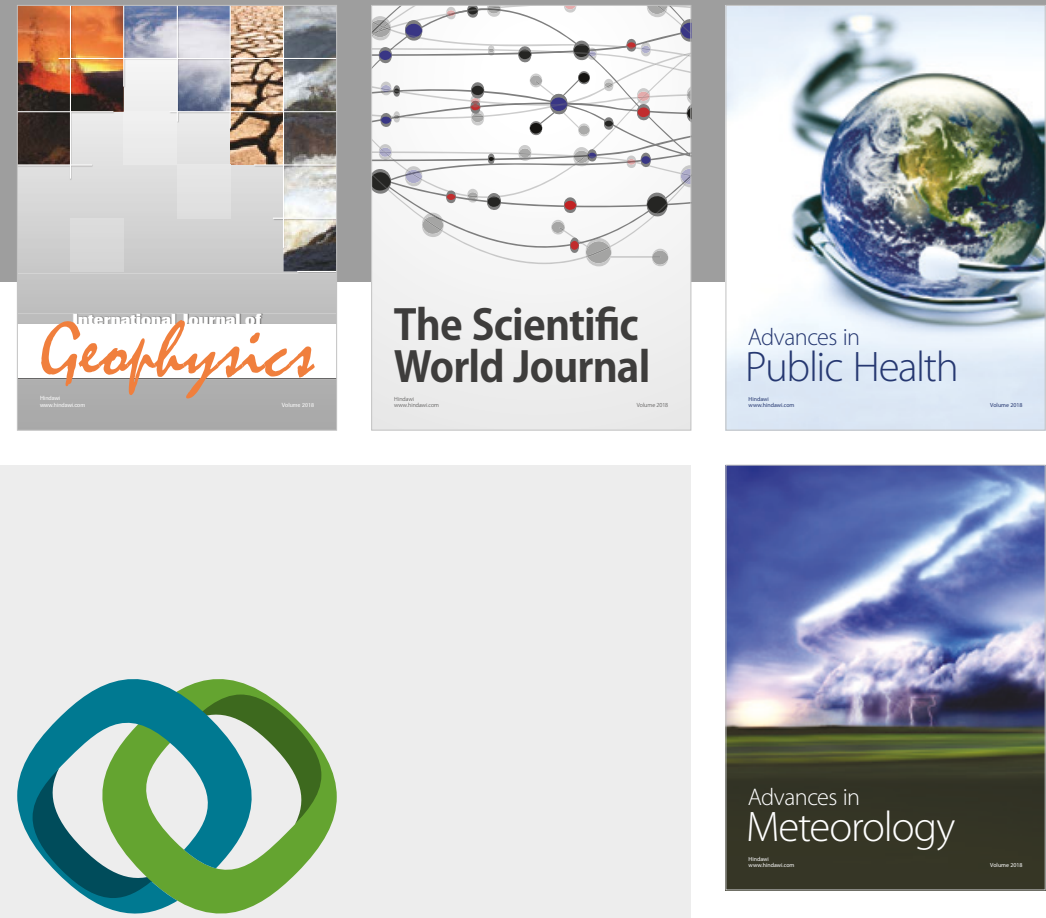

Advan

Public Health

\section{Hindawi}

Submit your manuscripts at

www.hindawi.com
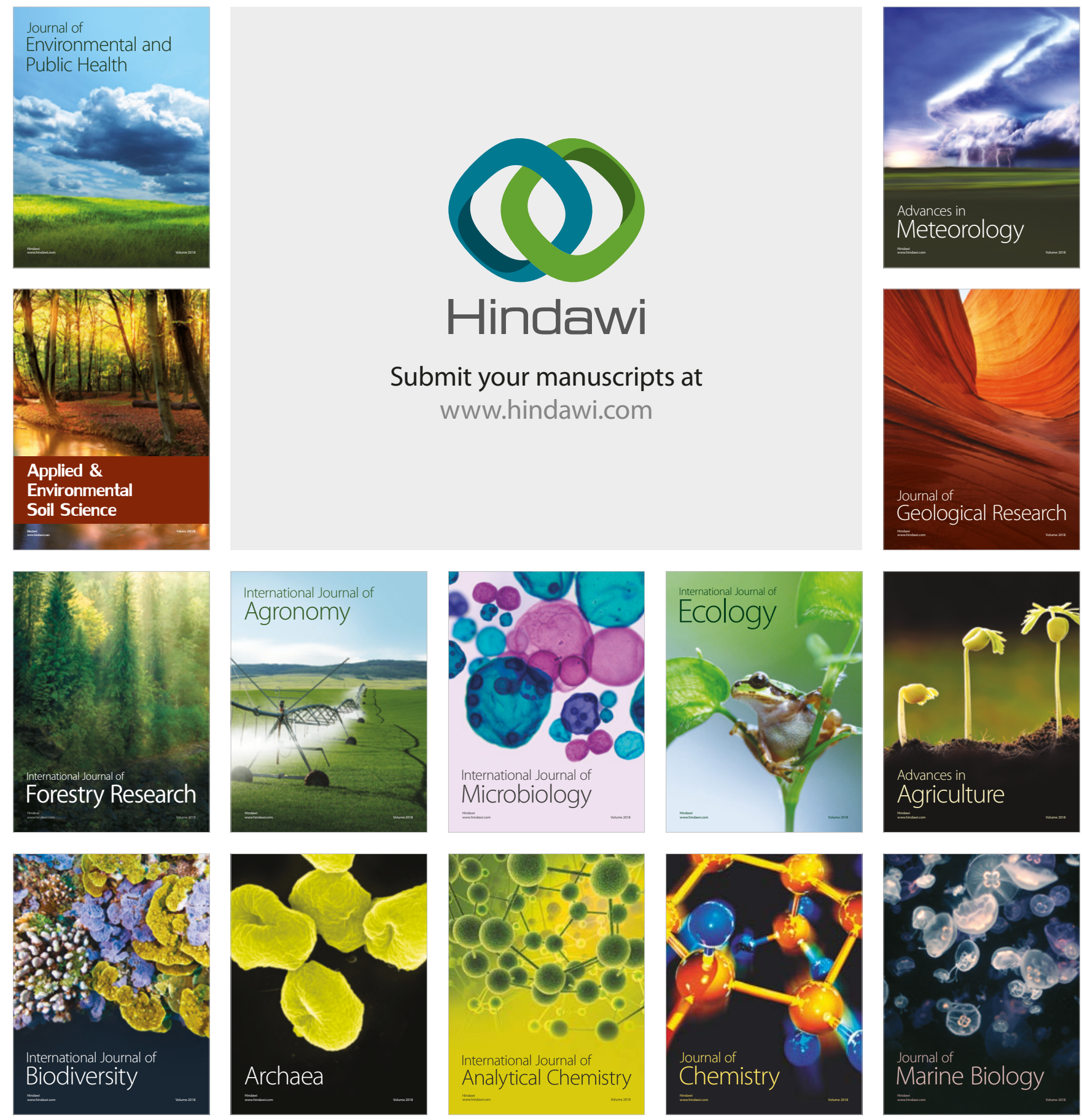